MATEC Web of Conferences 9, 03010 (2013)

DOI: $10.1051 /$ matecconf/20130903010

(C) Owned by the authors, published by EDP Sciences, 2013

\title{
Facade fire - fire safety engineering methodology
}

\author{
Franck Didieux ${ }^{\mathrm{a}}$ \\ Laboratoire National de Métrologie et d'Essais (LNE), Trappes, France
}

In France, Fire Safety regulations are essentially prescriptive. Their main safety objective is to preserve life, through the complete evacuation of occupants. The construction solutions that fulfill the regulatory corpus prescriptions are deemed to satisfy the safety objectives.

For external thermal insulation systems - installed on concrete or masonry walls - other systems than those deemed satisfactory may be implemented. Chapter 5.3 of Technical Instruction $\mathbf{n}^{\circ} 249$ (IT249, appendix of the Order dated 2010/05/24 [1]) gives details on the conditions of application.

The methodology to be implemented shall provide evidence that the studied construction solutions do not worsen the conditions for fire spread, when compared with a solution that is deemed satisfactory, described in the previous chapters of IT249, and taken as a reference point.

With the growing pressure of environmental problems, the current trend is to increase buildings insulation in order to reduce energy waste. Concerning external thermal insulation, this trend leads to an increase of the insulation thickness, up to values exceeding those deemed satisfactory in terms of fire safety and described in the regulation. In this case, the methodology to be implemented comes to bring demonstration that for a given insulating product or a given insulating product family, increasing the thickness up to the maximal thickness considered in the study (alternative configurations) does not worsen the conditions for fire spread. The reference configuration is then the same insulating product or family of products, installed with a thickness that complies with regulation requirements.

The methodology proposed in this paper rely on theoretical aspects for fire spread on a vertical wall $[2,3]$, as well as tests at several scales (small, intermediate and full scale) and numerical simulations. It applies to an insulating product or a family of insulating products. In the latter case however, it should be determined which insulating product is representative of the family, that is to say having the worst performance in terms of fire spread.

The main principle of this methodology is based on the fact that for insulating products, thermal stimulation from a façade fire progresses slowly in the depth of the material. Thus, as long as this thermal wave has not propagated deep enough to be influenced by any difference in thickness, fire behaviour is necessarily the same for equal stimulations. As a result, during this time for penetration of the thermal wave, any divergence of fire behaviour may only come from differences in the singularities between the reference configuration and the alternative configurations.

Therefore, the different experimental scales are intended to:

- characterize the insulating material or its family in terms of fire behaviour at small scale (temperature for 5\% mass loss through TGA measurement, ignition temperature, critical heat flux through cone calorimeter [4] measurements [5], etc.). This step also gives input data required by calculations and numerical simulations within the study framework;

- characterize the insulating material or its family at an intermediate scale (Euroclass) [6];

- explore the behaviour of the singularities of the construction solution at an intermediate scale. The chosen test reproduces a local impact of fire on a bay frame. The test bench is the NF EN 13823 [7] calorimeter;

\footnotetext{
ae-mail: franck.didieux@lne.fr
} 


\section{MATEC Web of Conferences}

- validate the whole approach by a real scale test on the insulating product representative of the worst fire behaviour within its family.

Provided that the behaviour of this insulating material is identical at all scales, and that it does not worsen the conditions for fire spread at real scale for the thicknesses targeted by the study, then these target thicknesses are acceptable within the regulatory framework.

These conclusions might be extended to other insulating products of the same family, provided their performance at intermediate scale testing are compatible with those of the studied representative insulating product.

\section{References}

[1] Instruction Technique $n^{\circ} 249$ relative aux façades (Annexée à l'Arrêté du 24 mai 2010 portant approbation de diverses dispositions complétant et modifiant le règlement de sécurité contre les risques d'incendie et de panique dans les établissements recevant du public; NOR: IOCE1014119A)

[2] J.G. Quintiere, A theoretical basis for flammability properties, Fire and Materials 2006, 30 : $175-$ 214

[3] J.G. Quintiere and Danjun Lian, Inherent flammability parameters - Room corner test application, Fire and Materials 2009, $33: 377-393$

[4] ISO 5660-1:2002 Reaction-to-fire tests - Heat release, smoke production and mass loss rate, Part 1: Heat release rate (cone calorimeter method)

[5] The SFPE Handbook of Fire Protection Engineering, 2nd edition, NFPA, 1995, ISBN-13: 9780877653547, §3, p56

[6] NF EN 13501-1+A1 Fire classification of construction products and building elements - Part 1: Classification using data from reaction to fire tests, AFNOR, ICS 13.220.50, ISSN 0335-3931

[7] NF EN 13823:2013 Reaction to fire tests for building products - Building products excluding floorings exposed to the thermal attack by a single burning item, AFNOR, ICS 13.220.50, ISSN 0335-3931 